Military Technical College

Kobry El-Kobbah,

Cairo, Egypt

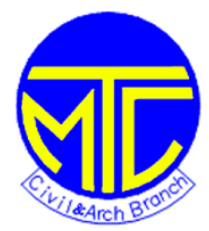

$11^{\text {th }}$ International Conference on Civil and Architecture

Engineering

ICCAE-11-2016

\title{
Behaviour of Hybrid Fibre-Reinforced ECC Composite Incorporating SMA Short Fibres under Effect of Impact Load
}

By

Mohamed A.E.M. Ali* Ahmed M. Soliman** Moncef L. Nehdi***

\section{$\underline{\text { Abstract: }}$}

The impact behaviour of an innovative hybrid-fibre engineered cementitious composite (ECC) incorporating randomly dispersed short shape memory alloy (SMA) fibres was experimentally investigated. A drop weight test was conducted on different ECC mixtures to evaluate their ability to dissipate energy and sustain multiple impact loads. The experimental results indicated that utilizing a combination of those fibres can significantly enhance the impact performance of ECC. Among the tested ECC mixtures, the one that incorporates 2\% PVA and 1\% NiTi-SMA presents the best energy dissipation ability at all testing ages. Therefore, incorporating SMA in composite materials, especially which exposed to impact loads, can be an effective strategy in constructing safer structures.

\section{Keywords:}

Shape memory alloy, engineered cementitious composite, hybrid-fibres, impact.

\footnotetext{
*Egyptian Armed Forces

**Western University, London, ON, Canada.

***Western University, London, ON, Canada.
} 


\section{Introduction:}

Concrete is one of the major construction materials being utilized worldwide. The penetration of high-velocity objects into soils, stones, metals, and concrete has historically been a subject of interest for structural engineers. The impact resistance of conventional reinforced concrete (RC) buildings depends mainly on its ability to dissipate energy upon impact events, blasts, and earthquakes. Partial or total collapse of RC buildings has been attributed to its inadequate capability to sustain such hazardous events [7]. Civil engineers are seeking new, smart and innovative construction materials in order to avoid such catastrophic failure mechanisms. Such materials are needed in constructing new smart buildings that achieve enhanced deformation capacity and ductility, higher damage tolerance, and ability to recover or reduce permanent deformations [8].

Smart materials have recently found numerous applications in many areas of civil engineering. A particularly interesting class of smart materials is known as shape memory alloys (SMAs). SMAs are a class of metallic alloys that have the ability to remember (memorize) their original shapes. They have the unique ability to undergo large inelastic deformation and regain its un-deformed shape when subjected to certain stimulus such as radiations, electric heating, thermo-mechanical, or magnetic variations. Effectively replacing traditional steel reinforcement by SMA rods has been reported by several researchers $[6,11$, and 12$]$.

Furthermore, over the last few decades, a unique high performance fibre-reinforced cementitious system known as engineered cementitious composites (ECCs) has emerged. It was coined and developed in 2001 by Li at the University of Michigan [9]. ECC is made of cement, supplementary cementing materials, micro-sand, and small amount of high modulus short random fibres. ECC features high ductility and damage tolerance against loading events. It is also categorized as a green material due to its high content of recycled by-products [9].

Therefore, this paper investigates the effect of NiTi-SMA fibre added at different percentages, namely $0.5 \%, 1 \%$ and $1.5 \%$, by volume fraction on the energy dissipation ability of PVA-ECC composites. The experimentally tested parameters include compressive strength, penetration-time history performance and cumulative energy dissipation, with and without heat treatment. 


\section{Experimental program:}

\subsection{Materials properties}

In this study, the ingredients used in the production of the different ECC mixtures include; (i) ordinary portland cement (OPC) which meets the ASTM C150 [1] (Standard Specification for Portland Cement) specifications with a specific gravity of 3.15 (main binder), (ii) class C fly ash (pozzolanic additive) as per ASTM C618 [4] (Standard Specification for Coal Fly Ash and Raw or Calcined Natural Pozzolan for Use in Concrete) with a specific gravity of 2.6, (iii) micro-silica sand as fine aggregate with a specific gravity of 2.65 and maximum nominal size of $200 \mu \mathrm{m}$, (iv) water presented as a percentage of the total cementitious materials, (v) polycarboxylate-based high range water reducer (HRWR) according to ASTM C494 [3] (Standard Specification for Chemical Admixtures for Concrete) with a specific gravity of 1.06 to enhance the workability of the mixtures, (vi) polyvinyl alcohol (PVA) short fibres having $8 \mathrm{~mm}$ in length, $39 \mu \mathrm{m}$ in diameter, $1300 \mathrm{~kg} / \mathrm{m}^{3}$ density, $42.8 \mathrm{GPa}$ elastic modulus and $1620 \mathrm{MPa}$ tensile strength, and (vii) nickel-titanium shape memory alloy (NiTi-SMA) short fibres which meets the ASTM F2063 [5] (Standard Specification for Wrought NickelTitanium Shape Memory Alloys for Medical Devices and Surgical Implants) having 16 $\mathrm{mm}$ in length, $625 \mu \mathrm{m}$ in diameter, density of $6450 \mathrm{~kg} / \mathrm{m}^{3}$ density, elastic modulus of 41 $\mathrm{GPa}$ and a tensile strength of $869 \mathrm{MPa}$.

\subsection{Mixture proportions}

Four different ECC mixtures were prepared and tested in this study. All ingredients of the ECC mixtures were kept constant except for the SMA fibre content. The ECC mixtures incorporate $60 \%$ of fly ash at as replacement for cement, $80 \%$ silica sand by weight of cement, $26 \%$ water and $1.2 \%$ HRWR by weight of all binder materials, $2 \%$ PVA fibres by volume fraction of the total ingredients, and SMA fibres added at different percentages by volume fraction $(0.5 \%, 1 \%$ and $1.5 \%)$. The ECC mixtures were labeled such that the ingredients are identifiable from their IDs as shown in Fig. 1. For example, the control mixture ECC2-0 incorporates $2 \%$ by volume fraction PVA, while it did not contain SMA fibres. All tests were performed 7 and 28 days after casting.

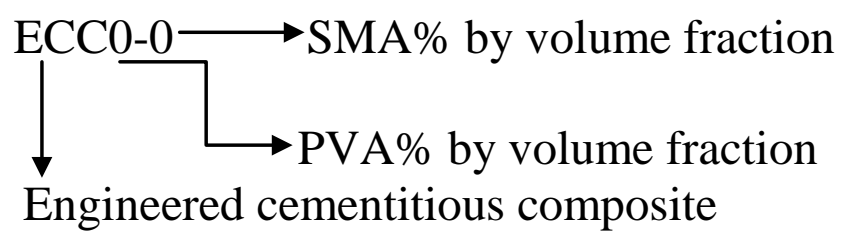

Figure (1): Specimen identification. 


\section{$\underline{2.3 \text { Casting and curing }}$}

In this experimental study, a mixer having $20 \mathrm{~L}$ capacity was used to prepare all the ECC mixtures. Solid ingredients including cement, fly ash, and silica sand were first mixed dry for one min. Subsequently, water and HRWRA were manually mixed together then added into the dry mixture and mixing resumed for another three minutes. Thereafter, the PVA and SMA fibres were added in the last step and mixing continued for an additional three minutes until fibres were uniformly distributed. All specimens were prepared by directly pouring the mixture into molds without compaction. After 24 $\mathrm{h}$ from casting, all specimens were demolded and kept inside sealed bags for 7 days and then stored at ambient lab conditions of $55 \pm 5 \%$ relative humidity and $20 \pm 2{ }^{\circ} \mathrm{C}$ until testing.

\section{Testing methods:}

This experimental study aims to explore the effects of SMA fibre addition with different percentages $0.5 \%, 1 \%$ and $1.5 \%$ by volume fraction on the compressive strength and impact resistance of ECC composites. The testing program was organized as follows;

\subsection{Compressive strength}

From each ECC mixture, three cubic specimens of $50 \mathrm{~mm}$ x $50 \mathrm{~mm}$ x $50 \mathrm{~mm}$ were prepared for the determination of the compressive strength of the different ECC mixtures as per the guidelines of ASTM C39 [2] (Standard Test Method for Compressive Strength of Cylindrical Concrete Specimens) using an MTS testing machine with capacity of $2000 \mathrm{kN}$. All cubic specimens were tested at the ages of 7, 14 and 28 days.

\subsection{Drop-Weight impact test}

Freshly mixed ECC specimens were cast in $100 \mathrm{~mm}$ x $200 \mathrm{~mm}$ cylindrical moulds. From these cylindrical specimens, three discs of $100 \mathrm{~mm}$ in diameter and $50 \mathrm{~mm}$ in thickness were cut using a diamond saw. Then, the discs were subjected to a drop weight impact test using an Instron impact loading testing machine with a capacity of 44-kN impact load. Following the steps suggested by [10], the test was conducted by applying multiple impact load in the form of blows, using a $201 \mathrm{kN}$ cylindrical steel impactor falling from different drop-levels $(50 \mathrm{~mm}, 100 \mathrm{~mm}$, and $150 \mathrm{~mm}$ ) on a solid steel ball of $50 \mathrm{~mm}$ diameter, placed at the center of the top surface of the cylindrical specimen. Furthermore, a similar test was conducted on another series of heat-treated ECC specimens to explore the pre-stressing effect of NiTi-SMA fibres on ECC specimens. 
The heat treatment was conducted for 10 minutes at a distance of $35 \mathrm{~mm}$ away from the front face of ECC specimens using a $520^{\circ} \mathrm{C}$ capacity heat gun. Data was acquired using an automated data acquisition system connected to the testing machine.

\section{Results and Discussion:}

\subsection{Compressive strength}

The variation in compressive strength for the different ECC mixtures at 7, 14 and 28 days is illustrated in Fig. 2. It can be observed that the SMA fibre addition induced a slight decrease in compressive strength of the composite at all testing ages. For example, at 28 days, the compressive strength of the ECC2-0.5, ECC2-1 and ECC2-1.5 mixtures decreased by about $5.2 \%, 4.8 \%$ and $3.0 \%$, respectively, compared to that of the ECC2-0 mixture. This is likely due to the decrease in workability caused by SMA fibre addition, which increased porosity of the composite, leading to decreased compressive strength. As expected, the compressive strength of the composite was enhanced when the curing age was prolonged due to the progress of the cement and fly ash hydration reactions, which in turn improved the fibre-matrix interface frictional bond resistance. For instance, at 28 days, all ECC specimens achieved about $48 \%$ and $15 \%$ higher strength than that of 7 and 14 days, respectively.

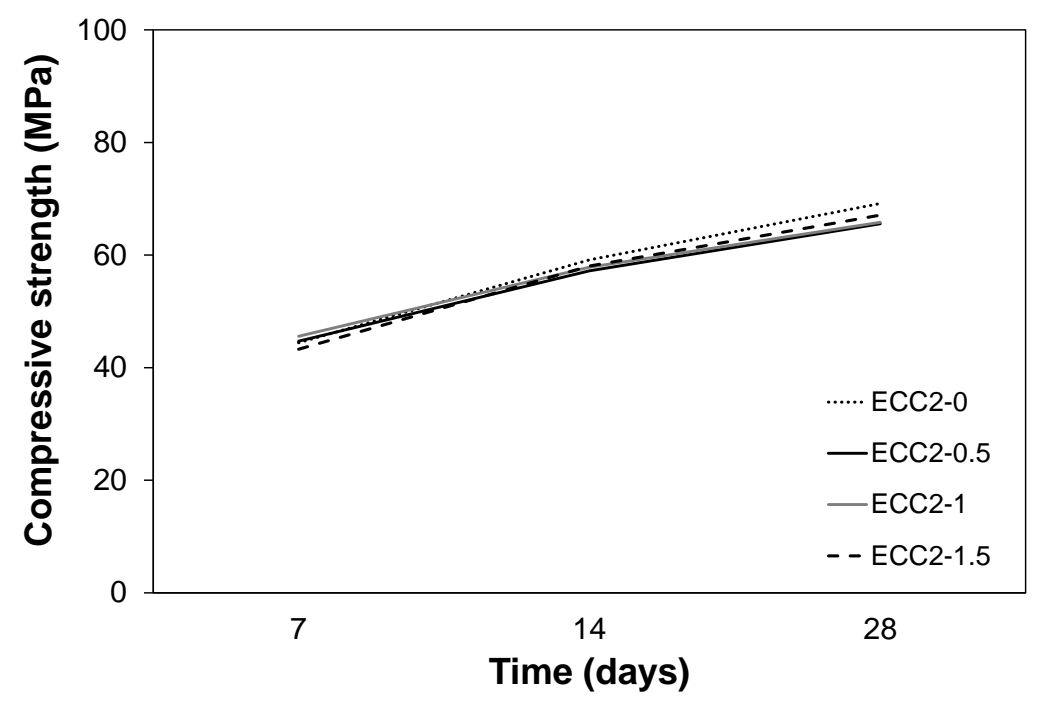

Figure (2): Compressive strength for ECC specimens. 


\subsection{Impact behaviour}

\subsubsection{Energy dissipation}

The enhancement in energy dissipation capability of specimens produced from different ECC mixtures is illustrated in Fig. 3. Generally, the energy dissipation capability was enhanced due to SMA fibre addition. For instance, at 7 days, the ECC2-0.5, ECC2-1 and ECC2-1.5 specimens dissipated energy of about 26.25\%, 32.76\% and $14.90 \%$, respectively, higher than that of the control ECC2-0 at the same testing age. Similar performance was observed at 28 days. The ECC2-0.5, ECC2-1 and ECC2-1.5 specimens dissipated energy of about $30.1 \%, 30.4 \%$ and $13.8 \%$, higher than that of the specimen made with PVA fibres alone at the same testing age, respectively. This reflects the significant enhancement in impact resistance of the composite due to SMA fibre addition.

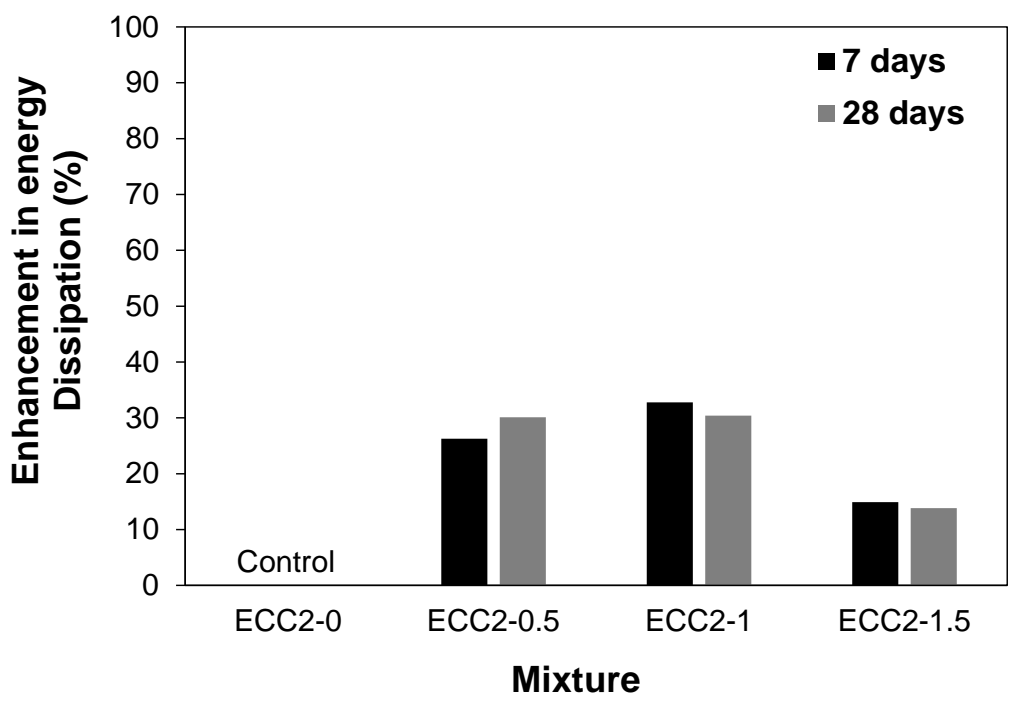

Figure (3): Enhancement in energy dissipation ability of different ECC specimens.

On the other hand, an overall improvement in the energy absorption capacity of the ECC composite was observed at 28 days compared to that at 7 days. For instance, at 28 days, the energy dissipation capacity of the ECC specimens improved by about $4 \%$ to 9\% compared to that of 7 days depending on the SMA fibre content. This may be attributed to the presence of high volume fly (more than half the cementitious materials) in the mixtures, which gained more strength at later ages, consequently, improving the fibre-matrix interfacial frictional bond strength. 


\subsubsection{Penetration-time history}

Figure 4 illustrates the penetration-time history of the different ECC specimens at testing ages of 7 and 28 days. All ECC specimens did not fail or even crack under the effect of multiple impacts up to $44 \mathrm{kN}$ (maximum capacity of testing machine). The penetration depth of the different ECC specimens at testing ages of 7 and 28 days is portrayed in Figure 5. Each specimen was subjected to multiple impacts at different drop heights such that the first, second and third hit was at $50 \mathrm{~mm}, 100 \mathrm{~mm}$ and 150 $\mathrm{mm}$, respectively, measured from the upper end of the steel ball up to the lower end of the impactor.
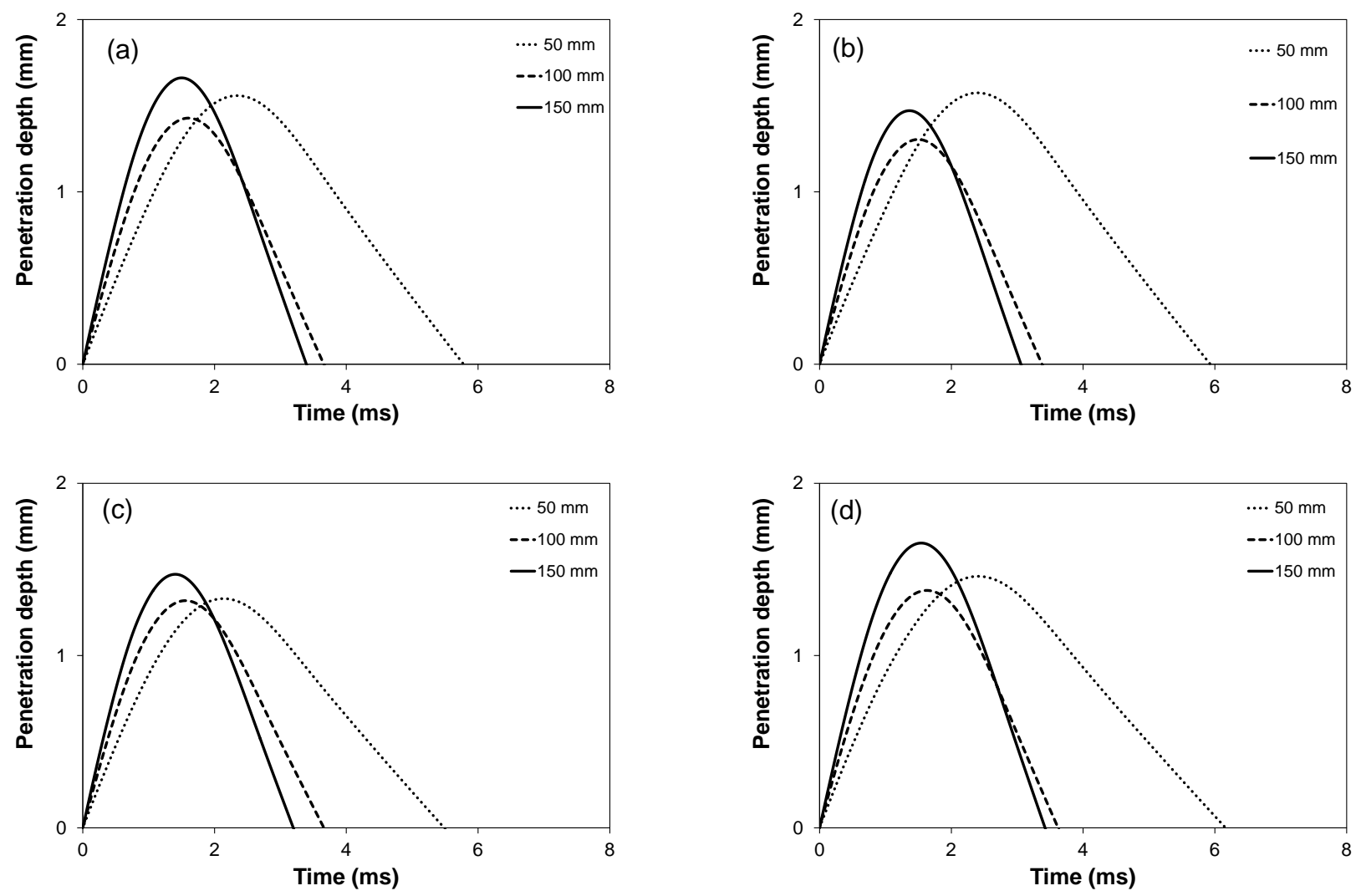

Figure (4): Typical penetration-time history of ECC specimens at testing age of 28 days a) ECC2-0, b) ECC2-0.5, c) ECC2-1, and d) ECC2-1.5. 




Figure (5): Penetration depth in ECC specimens at different testing ages.

As displayed in Fig. 5, it can be observed that only a small penetration took place due to impact loading. The penetration depth tended to decrease due to SMA fibre addition at all testing ages. For example, compared to that of the ECC2-0, the ECC2-0.5, ECC2-1 and ECC2-1.5 specimens had a lower penetration depth at 7 days by about $5.99 \%$, $9.48 \%$ and $2.90 \%$, respectively, and $6.45 \%, 11.4 \%$ and $3.44 \%$ at the age of 28 days, respectively. Likewise, the penetration depth generally decreased when the curing age was prolonged, regardless of the fibre type and content. For instance, the penetration depth of the ECC specimens tested at 28 days was lesser than that tested at 7 days by up to $10 \%$ to $12 \%$ depending on fibre type and content. This may be attributed to the high resistance of the fibre-matrix interface frictional bond in more mature specimens.

\subsubsection{Pre-stressing effect}

A heat treatment process was carried out on another series of similar ECC specimens to investigate the shape memory effect of SMA fibres and how it affects the overall performance of the composite under impact loading. Generally, applying heat treatment of up to $300^{\circ} \mathrm{C}$ for the specimens led to the formation of multiple hairline cracks, of less than $10 \mu \mathrm{m}$ width, at the front surface of specimens, which faced the heat gun's nozzle. Also, the heat treatment led to a strength degradation in the ECC specimen made with PVA fibres alone due to the melting of the fibres close to the heating nozzle. For example, as demonstrated in Fig. 6, the energy absorption capacity of the heated ECC20 specimen decreased by about $9.9 \%$ compared to that of non-heated similar specimen at the same testing age. 


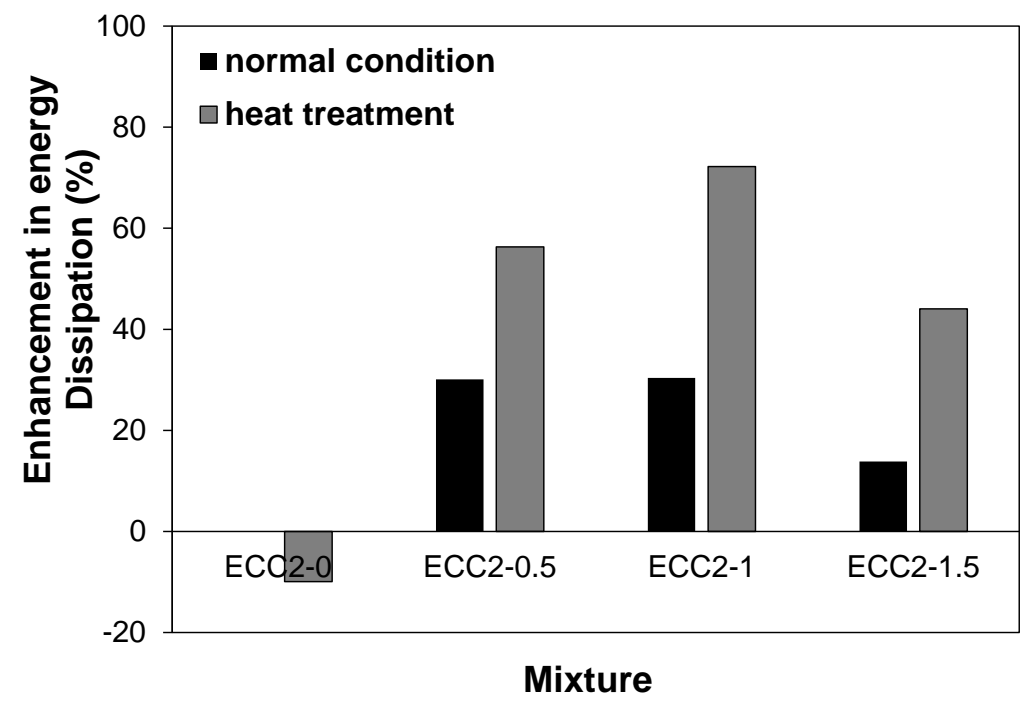

Figure (6): Effect of heat treatment on energy dissipation capability of different ECC specimens at 28 days.

On the other hand, the hybrid SMA fibre-reinforced specimens displayed different behaviour due to heating process as shown in Fig. 6. For instance, at testing age of 28 days, the energy absorption capacity of the heated ECC2-0.5, ECC2-1 and ECC2-1.5 specimens increased by about $20.1 \%, 32.0 \%$ and $26.6 \%$, respectively, compared to that of similar non-heated specimens at the same testing age. This is attributed to the fact that heating up of the specimens could mobilise the re-centering of SMA fibres due to its shape memory effect, which led to pre-stressing the specimens and consequently improving its energy absorption capacity.

\section{Conclusions:}

The following conclusions were drawn from the experimental study;

- The compressive strength of the composite slightly decreased due to SMA fibre addition.

- By adding $0.5 \%, 1.0 \%$ and 1.5\% volume fraction of NiTi-SMA fibres, the energy absorption capacity of the composite at the ages of 7 and 28 days increased by about $26.3 \%$, 32.8\%, $14.9 \%$ and $30.1 \%, 30.4 \%, 13.8 \%$, respectively, over that made of $2 \%$ PVA fibres alone.

- The results show that incorporating a combination of 2\% PVA and 1\% SMA fibres in the composite produced the highest energy absorption capacity at all testing ages compared to that of the other mixtures.

- An overall reduction was observed in the impact penetration depth of the ECC specimens, which incorporate SMA fibres compared to that of the other mixture made with PVA fibre alone. 
- The heat treatment process caused a deterioration in the matrix and PVA fibres. However, it was an effective way to motivate the SMA fibres to pre-stress the composite and work as a crack arrestor due to its shape memory effect. This performance led to an overall enhancement in the energy absorption capacity of the heated SMA-ECC composite over than of the non-heated one.

- This experimental study demonstrates the effectiveness of incorporating SMA fibres in the production of ECC composites, paving the way for safer structural applications.

\section{References:}

[1] ASTM C150/C150M, Standard Specification for Portland Cement, American Society for Testing and Materials, ASTM International, West Conshohocken, USA, 2015.

[2] ASTM C39/C39M, Standard Test Method for Compressive Strength of Cylindrical Concrete Specimens, American Society for Testing and Materials, ASTM International, West Conshohocken, USA, 2015a.

[3] ASTM C494/C494M, Standard Specification for Chemical Admixtures for Concrete, American Society for Testing and Materials, ASTM International, West Conshohocken, USA, 2015a.

[4] ASTM C618, Standard Specification for Coal Fly Ash and Raw or Calcined Natural Pozzolan for Use in Concrete, American Society for Testing and Materials, ASTM International, West Conshohocken, USA, 2015.

[5] ASTM F2063, Standard Specification for Wrought Nickel-Titanium Shape Memory Alloys for Medical Devices and Surgical Implants, American Society for Testing and Materials, ASTM International, West Conshohocken, USA, 2012.

[6] E. Choi, J.W. Hu, J. Lee, and B. Cho, Recovery Stress of Shape Memory Alloy Wires Induced by Hydration Heat of Concrete in Reinforced Concrete Beams, Journal of Intelligent Material Systems and Structures, Vol. 26, No. 1, P. 29-37, 2015.

[7] F. Alemdar, and H. Sezen, Shear Behaviour of Exterior Reinforced Concrete BeamColumn Joints, Structural Engineering and Mechanics, Vol. 35, No. 1, P. 123-126, 2010. 
[8] G. J. Parra-Montesinos, S.W. Peterfreund, and S. Chao, Highly Damage-Tolerant Beam-Column Joints through Use of High-Performance Fibre-Reinforced Cement Composites, ACI Structural Journal, Vol. 102, No. 3, P. 487-495, 2005.

[9] J. Marks, and J. Conklin, Engineered Cementitious Composites: Applications and Impact of High Tensile, Self-Healing Concrete. Online Paper, Swanson School of Engineering, University of Pittsburgh, Pennsylvania, USA, Vol. 3204, No. 5, 8 p., 2013.

[10] M. Nehdi, and A. Soliman, Novel Green Roofing Membrane System Made with Recycled Leftover Paint, Green Materials, Vol. 1, No. 4, P. 231-241, 2013.

[11] M. Nehdi, A. Shahria, and M. Youssef, Development of Corrosion-Free Concrete Beam-Column Joint with Adequate Seismic Energy Dissipation. Engineering Structures, Vol. 32, No. 9, P. 2518-2528, 2010.

[12] M. Saiidi, M. Zadeh, C. Ayoub, and A. Itani, A Pilot Study of Behaviour of Concrete Beams Reinforced with Shape Memory Alloys, Journal of Materials in Civil Engineering, Vol. 19, No. 6, P. 454-461, 2007. 